\title{
Ripple Filter for the 10,000A Superconducting Magnet Test Stand at the Magnet Test Facility
}

\author{
E. Drennan \\ Fermi National Accelerator Laboratory \\ P.O. Box 500, Baravia, Illinois 60510
}

November 1991 


\section{Disclaimer}

This report was prepared as an account of work sponsored by an agency of the United States Government. Neither the United States Government nor any agency thereof, nor any of their employees, makes any warranty, express or implied, or assumes any legal liability or responsibility for the accuracy, completeness, or usefullness of any information, apparatus, product, or process disclosed, or represents that its use would not infringe privately owned rights. Reference herein to any specific commercial product, process, or service by trade name, trademark, manufacturer, or otherwise, does not necessarily constitute or imply its endorsement, recommendation, or favoring by the United States Government or any agency thereof. The views and opinions of authors expressed herein do not necessarily state or reflect those of the United States Government or any agency thereof. 
TM-1764

Cat. 2080.000

Erika Drennan

November. 1991

\section{RIPPLE FILTER FOR THE 10,000A SUPERCONDUCTING MAGNET TEST STAND AT THE MAGNET TEST FACILITY}




\section{TABLE OF CONTENTS}

1. INTRODUCTION

2. VOLTAGE RIPPLE

Page 1

3 CURRENT OVERSHOOT

Page 1

4. FILTER CROWBAR

Page 2

5. CHOOSING THE COMPONENTS

Page 4

6. CHOOSING THE RESISTOR

Page 5

7. CAPACITORS

8. ACKNOWLEDGEMENTS

Page 6

Page 6

9. REFERENCES

Page 7

Page 7

10. DRAWINGS

ATV012291MTF

ATV031491MTF

Pages 8 and 9 


\section{INTRODUCTION}

The new 10,000A dumpswitch [1] and dumpresistor [2] system at MTF required a $720 \mathrm{~Hz}$ filter to eliminate power supply ripple from the load. The new filter, shown in Figure 1, had two requirements:

1. Less then $1 / 2 \mathrm{Ap}$-p ripple current with a load current of $10,000 \mathrm{~A}$.

2. No or minimal overshoot when the current reaches flattop after it is ramped to $10,000 \mathrm{~A}$.

MTF magnets are ramped to their final current values at different ramp rates depending on the inductance and type of the magnet under test. The filter design was done with the help of PSPICE simulations. Most of the simulations that will be shown in this write-up were done using a $50 \mathrm{mH}$ magnet and a ramprate of $200 \mathrm{~A} / \mathrm{s}$. In order to study this filter with SPICE, two different simulations had to be done. Due to the relatively high frequency of the ripple when compared with the ramping times, if the ripple current was studied together with the overshoot, the simulations would have taken a very long time to run. Therefore the voltage ripple and the current overshoot were studied separately.

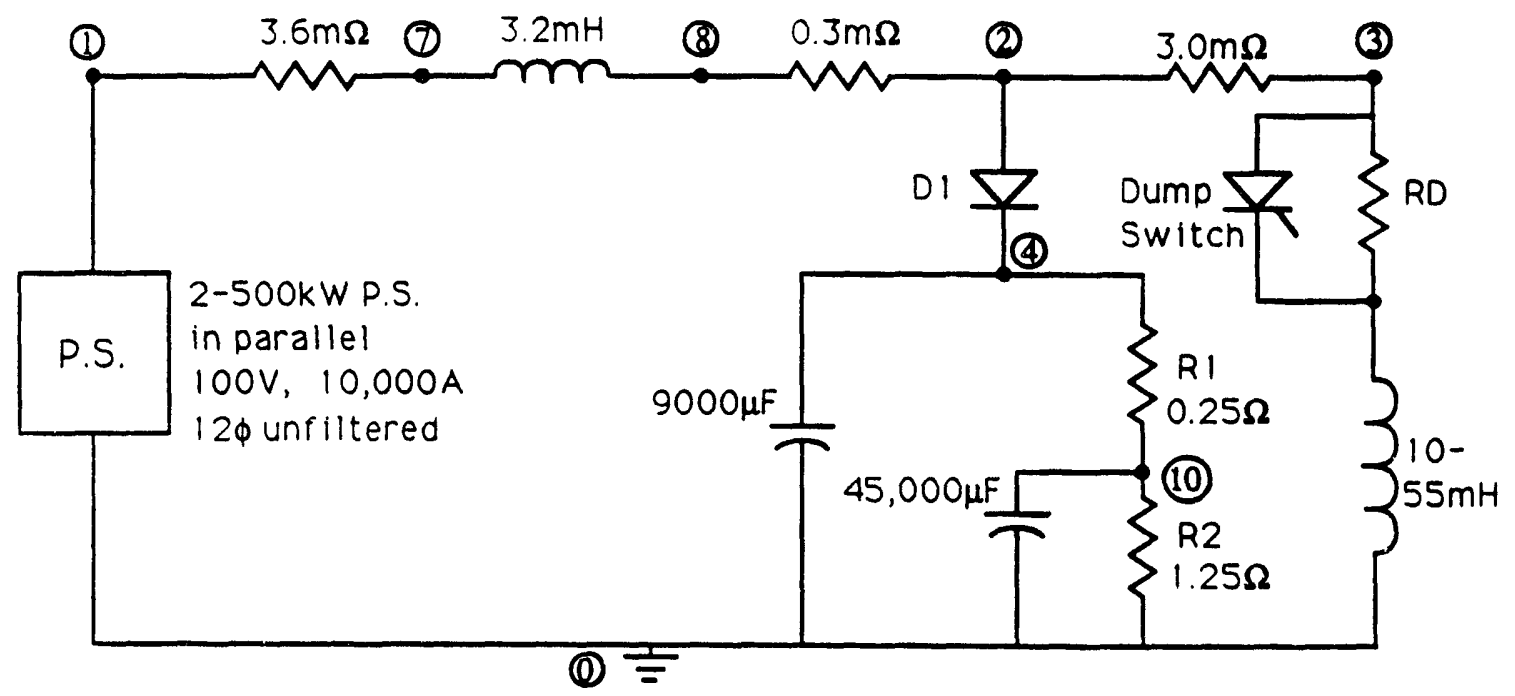

Figure 1: Filter configuration

\section{VOLTAGE RIPPLE}

Figure 2 shows the output ripple voltage that closely resembles the maximum ripple components of the $12 \phi$ unfiltered $500 \mathrm{~kW}$ power supplies. It also shows the voltage across the magnet. As it can be seen from this plot, the voltage across the magnet shows no ripple in it. Closer examination reveals that the magnet voltage ripple is only $\sim 50 \mathrm{mV}$, which indicates that the current ripple will remain under $1 / 2 A_{p}$-p. 


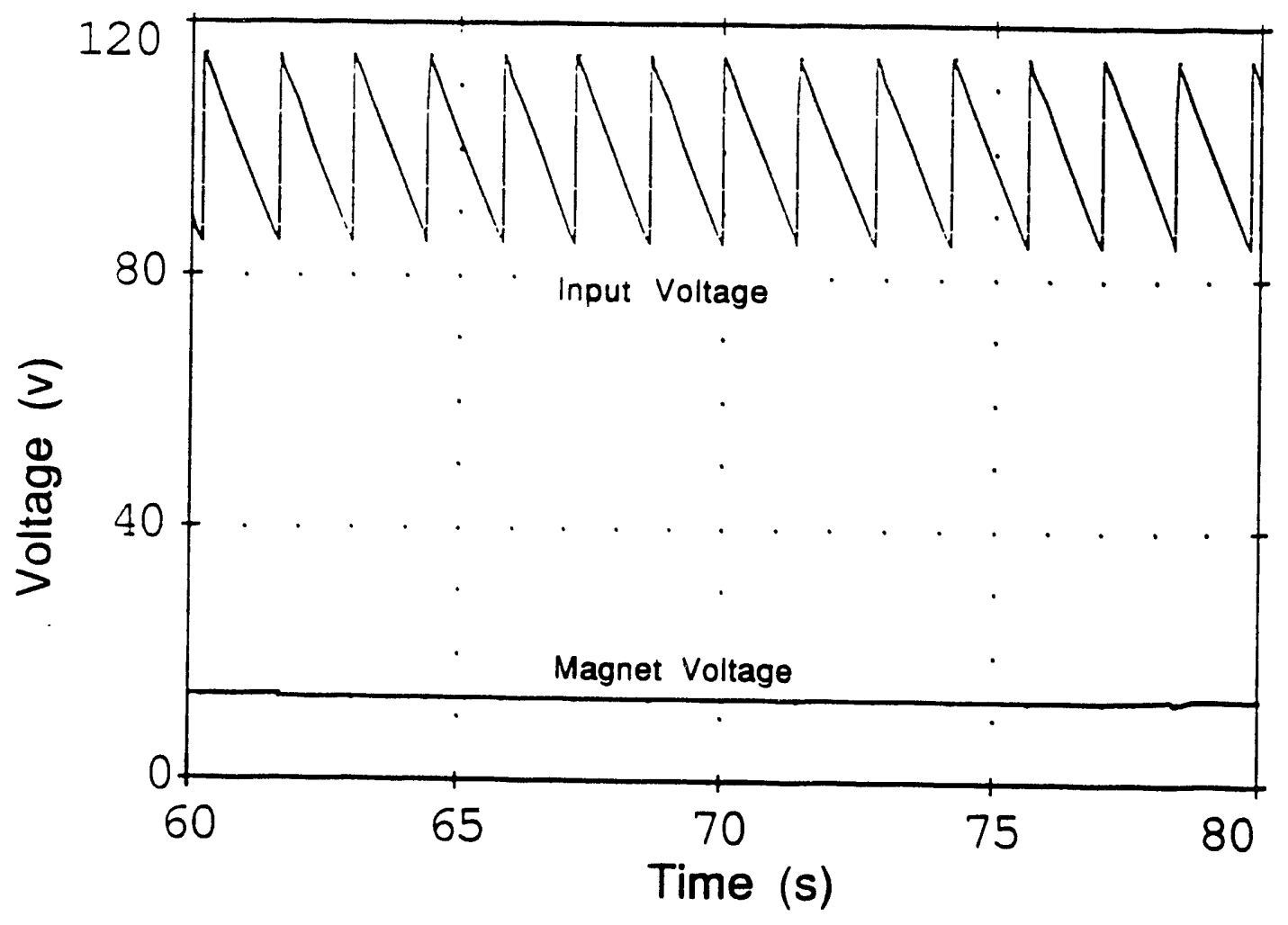

Figure 2: Voltage in and out of the filter

\section{CURRENT OVERSHOOT}

The current out of a power supply as it is ramped to $10,000 \mathrm{~A}$ at $200 \mathrm{~A} / \mathrm{s}$ is shown in Figure 3a. The current through the load due to this input looks very similar to the input, but if the area where the ramp reaches $10,000 \mathrm{~A}$ is enlarged as it is shown in Figure $3 \mathrm{~b}, \mathrm{a} \sim 3.5 \mathrm{~A}$ overshoot in the load current can be seen. This overshoot is due to a sharp reduction in power supply voltage as $\mathrm{d} / / \mathrm{dt}$ goes to zero. Although this overshoot is not too much, this value is the maximum theoretical overshoot that will be present in the current. The overshoot in the actual circuit will be smaller due to two reasons that could not be included in the SPICE models. One of these reasons is that actual power supplies are regulated from the load current, not from the power supply current as the SPICE model indicated. Since the power supply is regulated from the load current some of the overshoot caused by the filter would be compensated for by the regulator. The other reason why the actual overshoot would be smaller then indicated here, is that MTF magnets are ramped with the use of a special ramp module, which parabolically smooths rough edges in the voltage waveform. As changes in the power supply voltage become smoother, the current overshoot is also reduced. Several other filter configurations were tried, but it was found that in cases where the overshoot was further reduced, the ripple filtering ability decreased. The resistance value of increase losses. Therefore 2 (Fig. 1) affect the overshoot. Smaller values reduce overshoot, but increase losses. Therefore one consideration in choosing R1 and R2 was to keep the losses low. 


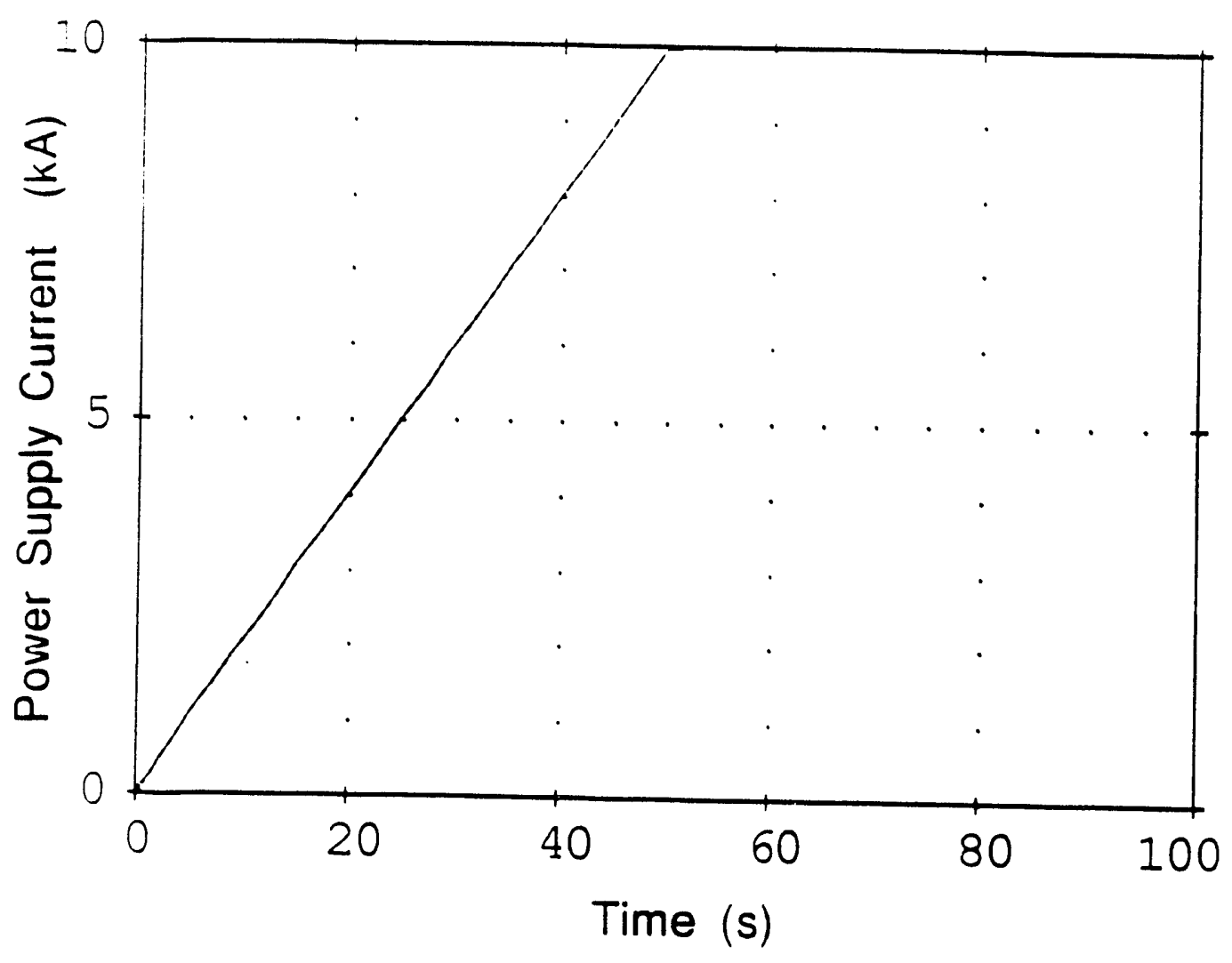

Figure 3a: Power supply output current

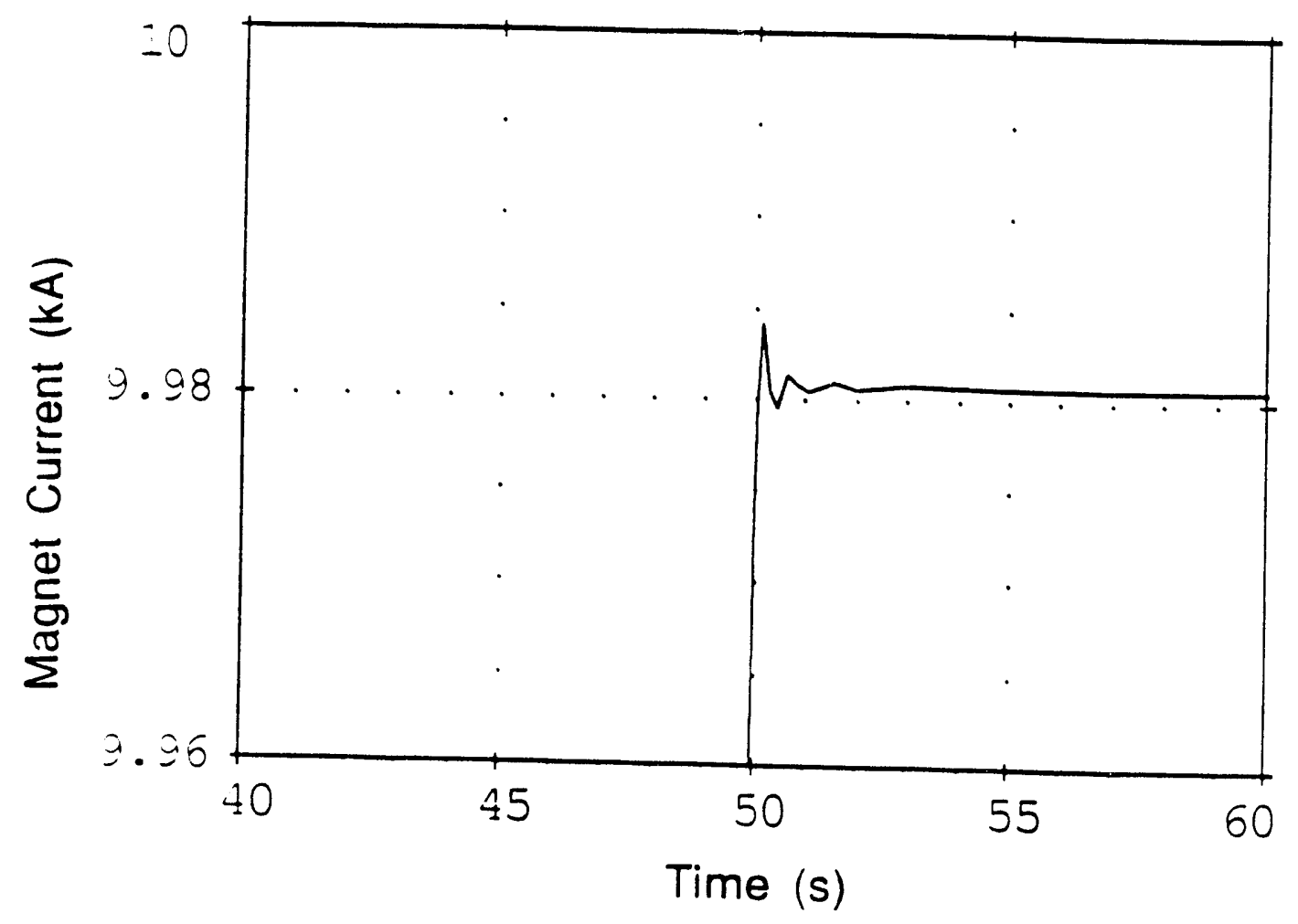

Figure 3b: Magnet current overshoot 


\section{FILTER CROWBAR}

As the complete dumpswitch circuit with the filter included was studied it was noticed that whenever there is a short for a load, which is often done when the system is tested, at the time the dumpresistor is put into the circuit, the voltage across the filter caps rises sharply to a very high value (close to 1000V). This can be easily seen by looking at Figure 4 . If the circuit is in steady state with $10,000 \mathrm{~A}$ through it, and the $100 \mathrm{~m} \Omega$ dump resistor is suddenly put into the circuit, for a short time this resistor will have almost all of the $10,000 \mathrm{~A}$ going through it, which would develop close to $1000 \mathrm{~V}$ across the capacitors. Since the filter capacitors are not rated for such a high voltage, a crowbar circuit was designed to short the capacitors in case of this sudden rise of voltage. PSPICE was again used to gain better understanding of how quickly the crowbar circuit had to be inserted across the capacitors. The surge voltage rating of the electrolytic filter capacitor bank is $300 \mathrm{VDC}$. To have a safety factor of $100 \mathrm{~V}$, the trip value of the crowbar is set at 200VDC. To know how long it takes the capacitor voltage to reacn $200 \mathrm{~V}$, the dump circuit, as shown in Figure 4, was modeled on PSPICE. In this figure the SCR represents the dumpswitch. A dump signal is initiated when the power supply voltage reaches zero. The plot of the input voltage and the voltage across the filter is shown in Figure 5. Looking at the plot, it can be seen, that the actual capacitor voltage reaches $-200 \mathrm{~V}$ in $\sim 200 \mu$ s after a dump signal is initiated. This means that a crowbar circuit had to be designed that would short the capacitors in $\sim 200 \mu s$. The final crowbar circuit consists of a frequency compensated voltage divider and a diac which fires a crowbar SCR whenever the voltage rises above $200 \mathrm{~V}$. The crowbar circuit along with the filter circuit is shown on drawing \#ATV012291MTF. A large crowbar SCR is chosen to withstand a possible unscheduled (failure) turn on during running conditions.

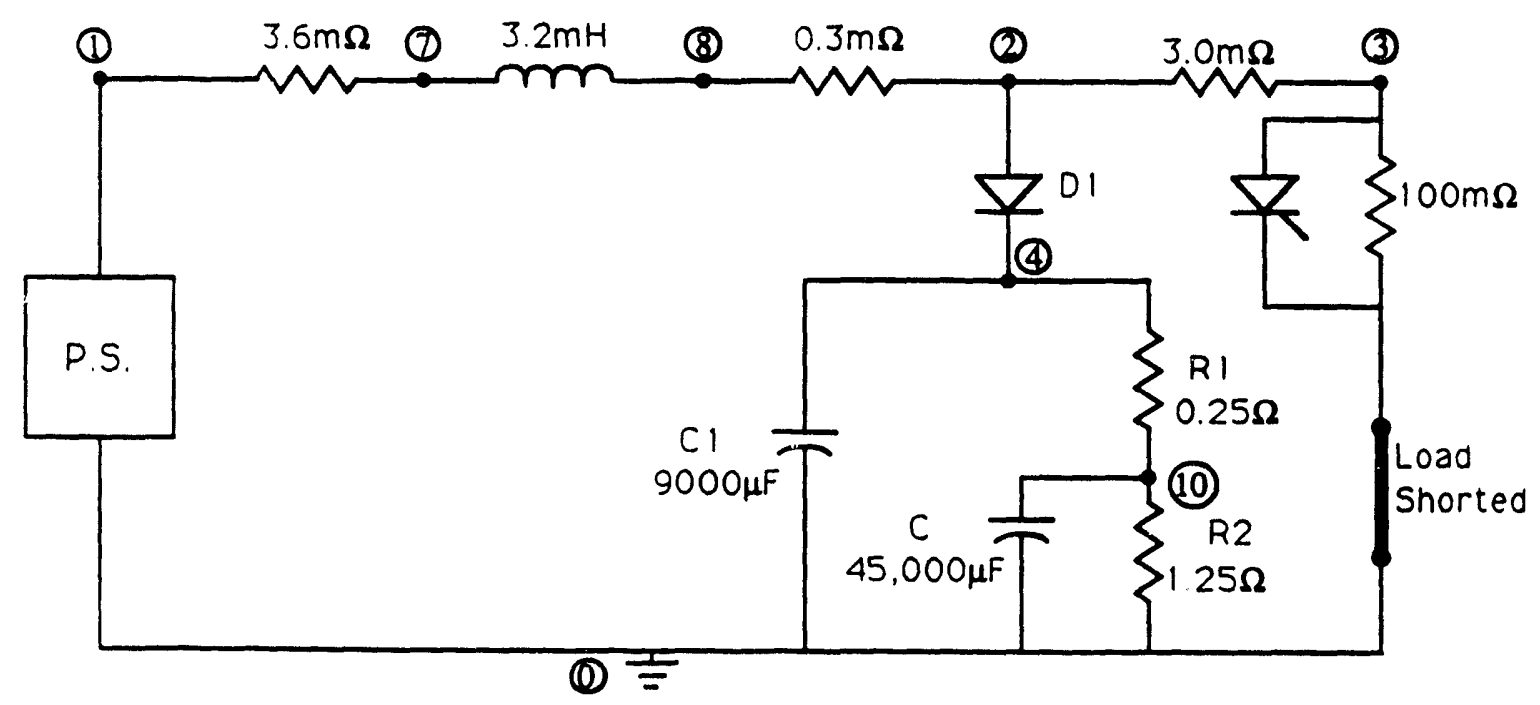

Figure 4: Circuit for testing the dump 


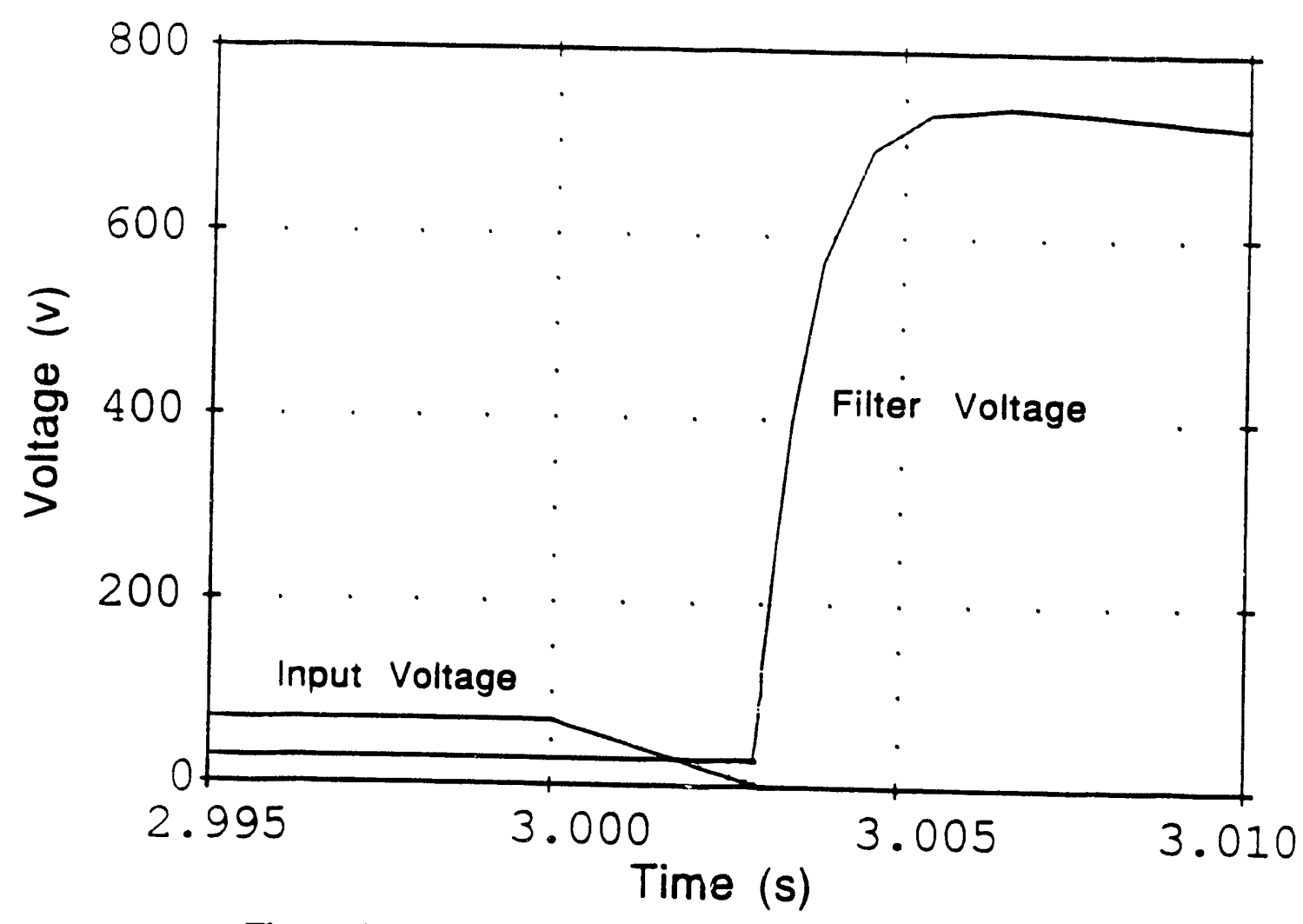

Figure 5: Filter voltage rise due to a dump with the load shorted

\section{CHOOSING THE COMPONENTS}

Once the design of the filter and the crowbar were done, the capacitors and the resistor had to be purchased. To study the maximum and steady state voltages and currents in the circuit, SPICE simulations were done. These simulations were done to determine the ratings of the individual components. To study the maximum voltages and currents during steady state, a simulation was done with no load attached to the system. The power supply was outputting $100 \mathrm{~V}$ with a $40 \mathrm{~V}_{0, p}$ ripple superimposed on it. The results of this simulation are given in Table 1.

Table 1: Maximum steady state values

\begin{tabular}{|c|c|}
\hline Component & Value \\
\hline$V(C 1)$ & $120 \mathrm{~V}$ \\
\hline$I(C 1)$ & $2.5 \mathrm{~A}_{\mathrm{p}-\mathrm{p}}$ \\
\hline $\mathrm{V}(\mathrm{C})$ & $100 \mathrm{~V}$ \\
\hline $\mathrm{I(C)}$ & $<1 \mathrm{Ap}-\mathrm{p}$ \\
\hline $\mathrm{I(D1)}$ & $80 \mathrm{~A}$ \\
\hline $\mathrm{P}(\mathrm{R} 2)$ & $8 \mathrm{~kW}$ \\
\hline $\mathrm{P}(\mathrm{R} 1)$ & $1.5 \mathrm{~kW}$ \\
\hline
\end{tabular}

To study the transient response of the filter, a $100 \mathrm{~V}$ step function was the voltage input. The maximum currents and power dissipated in the components, due to the step voltage, are given
in Table 2 . 
Table 2: Maximum values due to step input

\begin{tabular}{|c|c|}
\hline Component & Value \\
\hline $\mathrm{I}(\mathrm{D} 1)$ & $280 \mathrm{~A}$ \\
\hline $\mathrm{I}(\mathrm{C})$ & $190 \mathrm{~A}$ \\
\hline $\mathrm{I}(\mathrm{C} 1)$ & $60 \mathrm{~A}$ \\
\hline $\mathrm{P}(\mathrm{R} 2)$ & $9 \mathrm{~kW}$ \\
\hline $\mathrm{P}(\mathrm{R} 1)$ & $13 \mathrm{~kW}$ \\
\hline
\end{tabular}

\section{CHOOSING THE RESISTOR}

From Table 1, it can be seen that in the worst case situation with no load, the resistors have to dissipate a substantial amount of power. From Table 1, we get that the steady state power dissipated is $P\left(R_{1}\right)+P\left(R_{2}\right)$ which is $9.5 \mathrm{~kW}$. To purchase resistors, that could handle this power, would have been quite expensive. Also packaging them would have taken a lot of space. Therefore it was decided to use stainiess steel tubing to make a watercooled resistor. This has cut down the cost and the size of the resistor. The tubing that was chosen was $1 / 4 \times 22 \mathrm{SS}$. In order o calculate the length of the tubing required, the resistance/ft $(R / f t)$ of this tubing had to be calculated. The $\mathrm{R} / \mathrm{ft}$ can be calculated using the fact that a $\operatorname{lin}^{2} \mathrm{SS}$ bar has $\mathrm{R} / \mathrm{ft}=.34 \times 10^{-3} \Omega / \mathrm{ft}$ and it has a weight $/ \mathrm{ft}=3.4 \mathrm{lbs} / \mathrm{ft}$. The $1 / 4 \times 22 \mathrm{SS}$ tubing has a weight of $.0664 \mathrm{lbs} / \mathrm{ft}$. Using this information, the $\mathrm{R} / \mathrm{ft}$ of the SS tubing is calculated.

$$
\frac{\mathrm{R}}{\mathrm{ft}}=\frac{3.4}{.0664} \times .34 \times 10^{-3}=17.4 \mathrm{~m} \Omega / \mathrm{ft}
$$

we need $1.5 \Omega$

$$
1=\frac{1500 \mathrm{~m} \Omega}{17.4 \mathrm{~m} \Omega / \mathrm{ft}}=86.16 \mathrm{ft}
$$

Therefore the length of the tubing needed is $86.16 \mathrm{ft}$.

$1 \mathrm{GPM}$ of water flow is needed to take away $10 \mathrm{~kW}$ of heat generated in the resistors with a water temperature rise of $38^{\circ} \mathrm{C}$. The finished resistor was tested for the amoui. $\leftarrow$ of water that can flow through it and it was found that the flowrate at a $\triangle P=45$ PSI was $0.83 \mathrm{GPM}$. Therefore at a $\triangle \mathrm{P}$ of $100 \mathrm{PSI}$, which is the water pressure available at MTF, a flow-rate of $1 \mathrm{GPM}$ through the resistor should pose no problem. But just in case there is ever a loss of water flow in the resistor, the resistor is also protected by two $120^{\circ} \mathrm{C}$ klixons, which will trip off the power supply in case A drawing of the resistor with all of its actual specifications and ratings is given on the
drawing\# ATV031491MTF.

\section{CAPACITORS}

Table 1 was used to choose the capacitors also. From Table 1 it can be seen that the maximum steady state voltage across the caps is about $120 \mathrm{~V}$. For a safety factor of $2,250 \mathrm{WVDC}$ 
capacitors were chosen. The ripple current through these capacitors, even for the worst case ripple, is very small, therefore just about any capacitor can handle the ripple current. the maximum possible current values in Table 2 were used to choose proper values for the fuses which are used for circuit protection in case of capacitor failure.

\section{ACKNOWLEDGEMENTS}

Age T. Visser designed the resistors and the filter crowbar. He was also very helpful with his suggestions regarding the design of the filter. I am grateful for all his help.

Walt Jaskierny built and tested the filter. His contribution is appreciated.

\section{REEERENCES}

[1] TM\# 1161 Cat.\# 2080.000, A. T. Visser March '90, Design note of a 10,000A, 2MJoules Dump Resistor for the Magnet Test Facility.

[2] TM\# 1692 Cat.\# 2080.000, A. T. Visser October '90, Design note of a 10,000A, 1000VDC Solid State Dump Switch for the Magnet test Facility. 


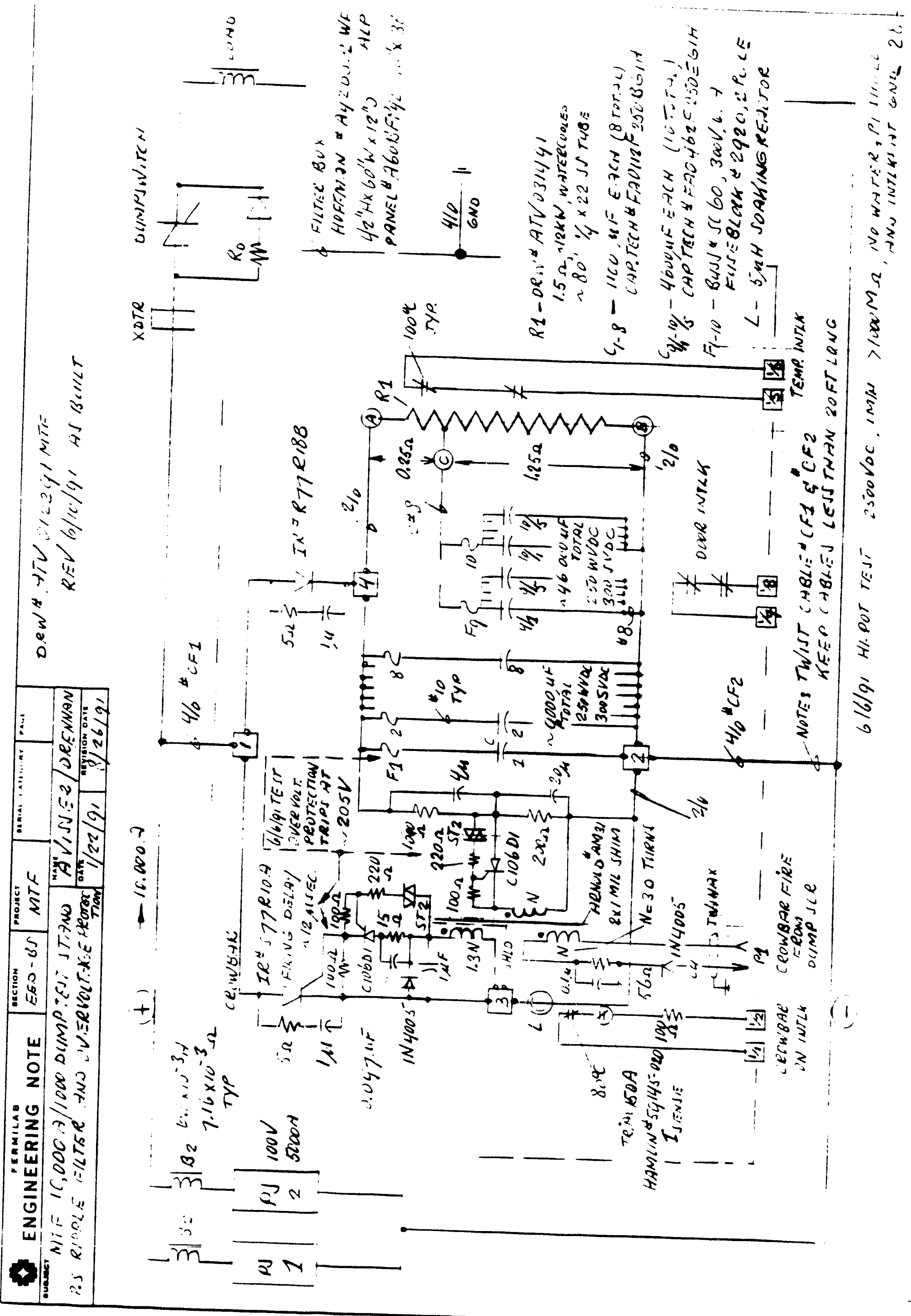




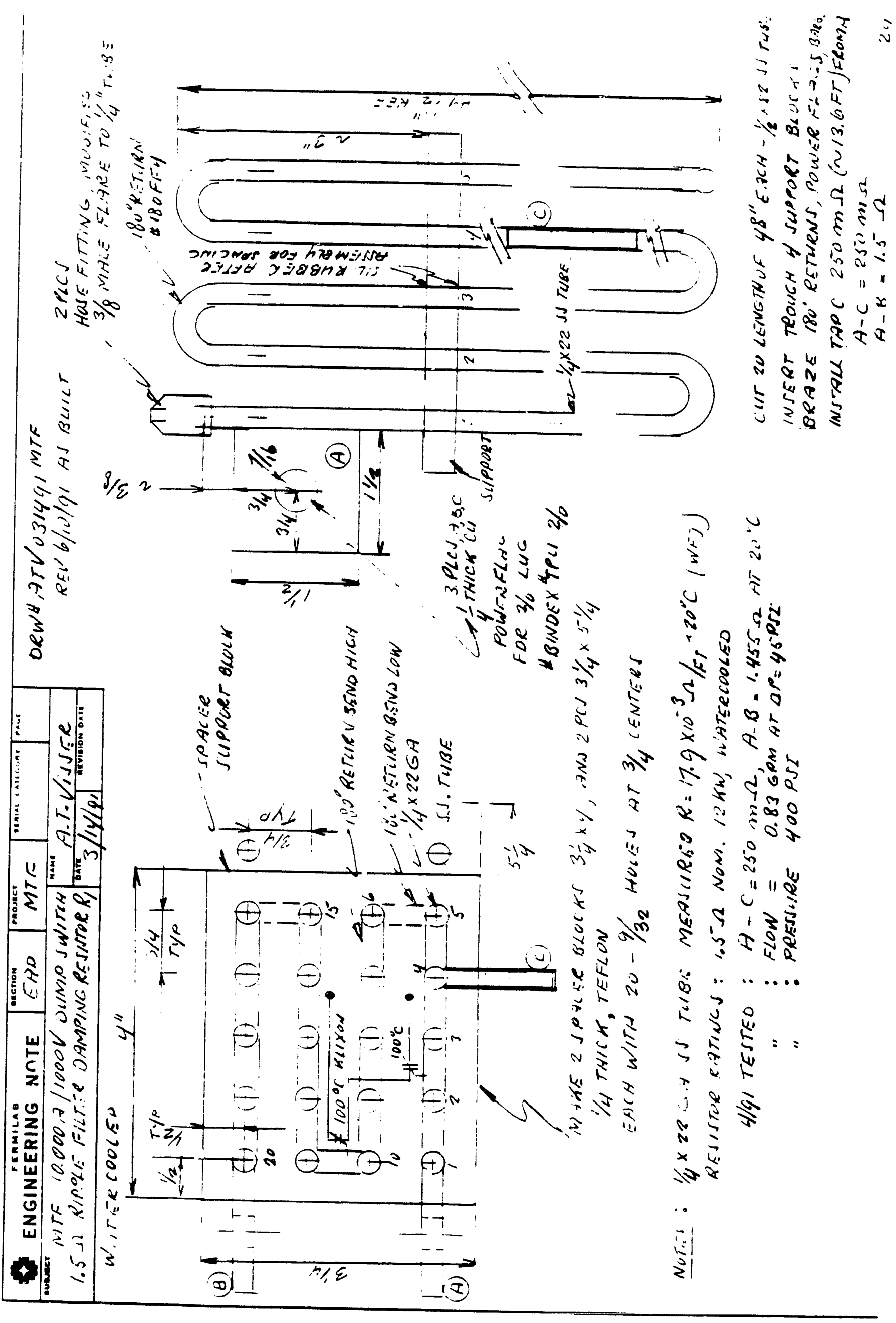



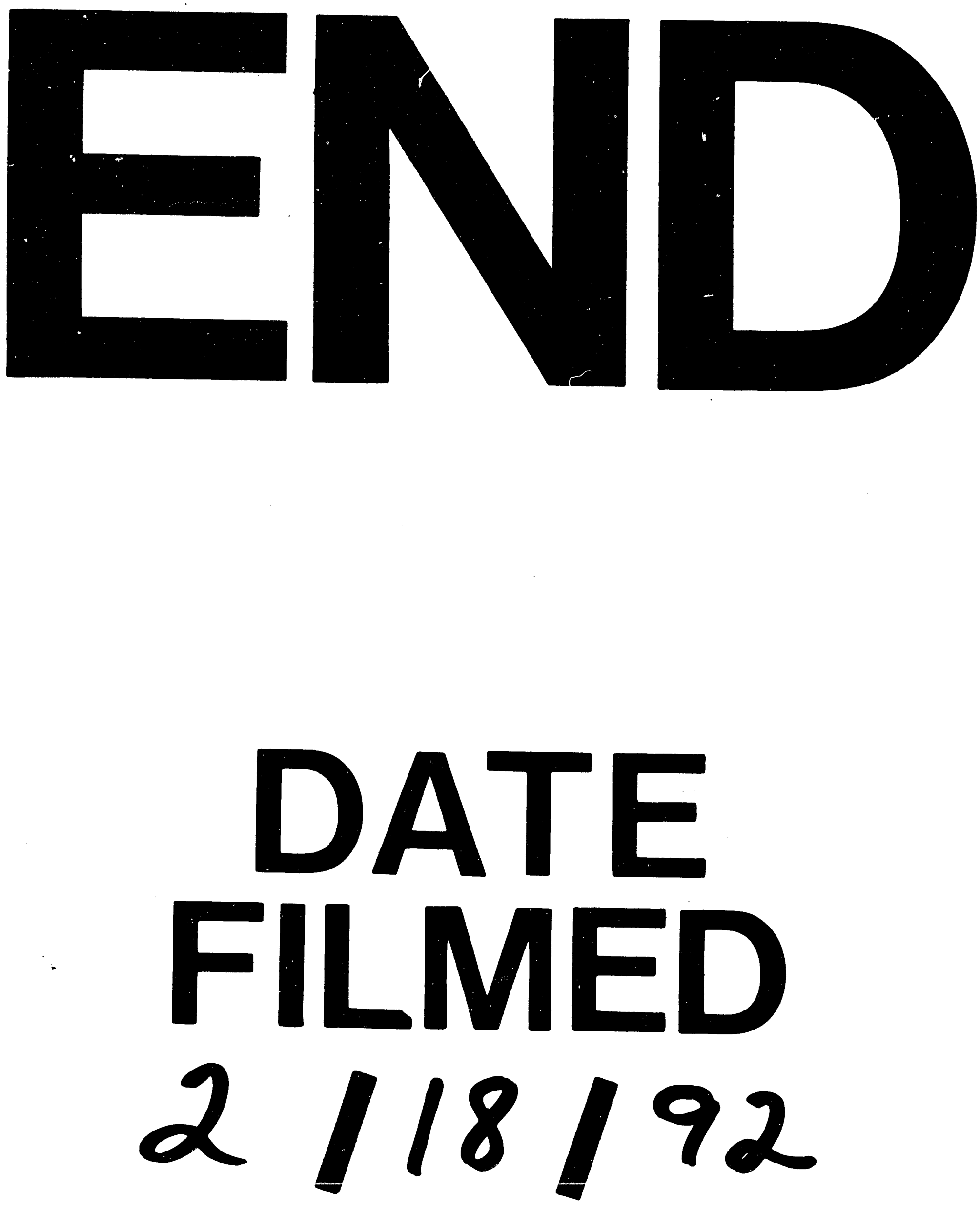


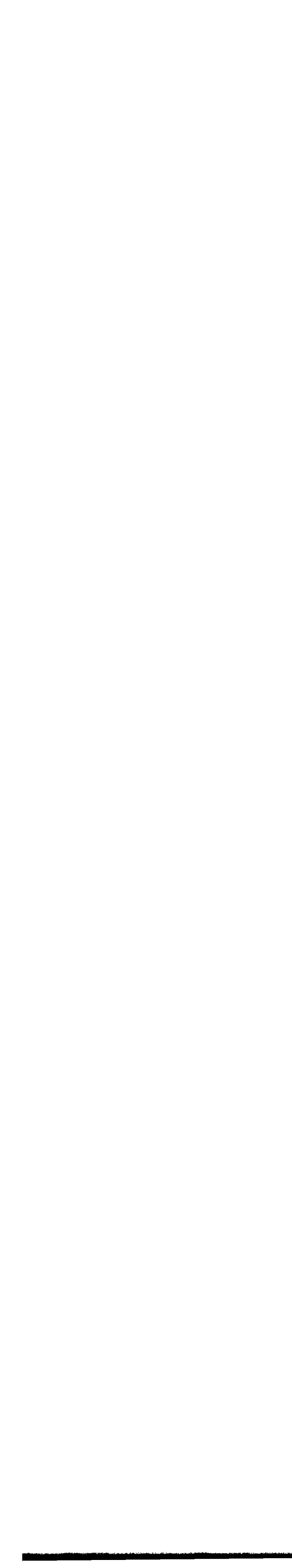

